\title{
Dabigatran Treatment Increased Closure Device- Related Thrombosis by Platelet Activation in Patients Undergoing Percutaneous Left Atrial Appendage Closure
}

\section{Xiaoye Li}

Zhongshan Hospital Fudan University

Xiaochun Zhang

Zhongshan Hospital Fudan University

Qinchun Jin

Zhongshan Hospital Fudan University

Yanli Li

Zhongshan Hospital Fudan University

Junbo Ge

Zhongshan Hospital Fudan University

Daxin Zhou

Zhongshan Hospital Fudan University

qianzhou Iv ( $\sim$ 13916088938@163.com )

Zhongshan Hospital Fudan University https://orcid.org/0000-0002-6353-7767

\section{Research Article}

Keywords: direct oral anticoagulations, percutaneous left atrial appendage closure, device related thrombosis, thrombin receptor activating peptide induced platelet aggregation, thrombin-antithrombin complex, P-selectin, von Willebrand disease.

Posted Date: March 31st, 2021

DOI: https://doi.org/10.21203/rs.3.rs-346548/v1

License: (c) (i) This work is licensed under a Creative Commons Attribution 4.0 International License. Read Full License 


\section{Abstract \\ Background}

This study was designed to evaluate the platelet reactivity of different antithrombotic regimens under the condition of occluder implantation.

\section{Methods}

A single, prospective cohort study was conducted among patients who received anticoagulation with either dabigatran $(\mathrm{N}=33)$ or rivaroxaban $(\mathrm{N}=72)$ between January 2018 and December 2019. We applied thromboelastogram (TEG) to evaluate platelet aggregation induced with thrombin receptor activating peptide (TRAP) after anticoagulation for 3 months. Plasma coagulation markers mediate platelet activation including TAT, P-selectin, VWF and CD40L were tested by the method of ELISA kit on the day of LAAC and at 3 months after operation procedure. Repeated transesophageal echocardiographic were scheduled to evaluate device related thrombosis (DRT) formation on occluders at 3-month after discharge.

\section{Results}

There was $3(4.2 \%)$ in rivaroxaban and $4(12.1 \%)$ in dabigatran group experiencing DRT events $(\mathrm{OR}=0.315$, $95 \% \mathrm{Cl}: 0.066-1.489, \mathrm{P}=0.129)$ during follow-ups. The TRAP induced platelet aggregation was higher for patients medication with dabigatran as compared to rivaroxaban group $\left(62.9 \%\right.$ vs. $\left.59.7 \%, P=0.028^{\star}\right)$. The plasma levels of TAT, P-selectin, vWF expression was significant higher after 3 months intake of dabigatran compared with that on the day LAAC operation, meanwhile, no significant difference was found in the changes of $\mathrm{CD} 40 \mathrm{~L}$ plasma levels. After receiving 3 months anticoagulation with rivaroxaban, the expressions of plasma platelet activation of TAT, P-selectin, VWF and CD40L showed no significant changes. We observed significant higher expressions of plasma platelet activation markers for DTR patients in terms of the P-selectin and vWF compared with non-DRT patients. Multivariate regression shwed that anticoagualtion regimen $(P=0.022 ; O R=4.366,95 \% \mathrm{Cl}$ : $0.434-10.839)$ was an independent predictor for DRT in patients after LAAC operation, while non of the plasma platelet activation included was associated with DRT.

\section{Conclusions}

By avoiding peri-procedure DRT occurrence, it is possible that dabigatran usage might even be reduced, as they had been shown to increase expressions of platelet reactivity.

\section{Introduction}


Currently, percutaneous left atrial appendage closure (LAAC) has become an effective and safe surgical method for the prevention of stroke, and it is mainly available for patients who are diagnosed with nonvalvular atrial fibrillation (NVAF) and cannot adhere to long-term anticoagulant therapy [1-3]. Recently, LAAC has been acknowledged as a reliable alternative for cardioembolic stroke prevention with an efficacy equal to anticoagulation therapy. It was defined that thrombosis in the left atrium can obviously increase the risk of stroke and about $90 \%$ of identified left atrium thrombosis are located in the left atrial appendage (LAA) [4]. Presently, during the medication with oral anticoagulation (OAC), LAAC operations raised a fascinating concept on the combination of potential reduction of thrombosis occurrence and bleeding events $[5,6]$.

Similar as other implanted devices in human body, when exposed to circulating blood after LAAC operations, there might be a necessary period for the complete endothelialization of occluders. The thrombus formation results from a local tissue response to an implantation and may occur on all available devices with endothelialization profiles that require adequate antithrombotic treatment to prevent device related thrombosis (DRT) [7-9]. Before fully closure endothelialization, there was a remarkable interindividual variability on post-anticoagulation, which might add uncertainness on anticoagulation duration for LAAC patients [10]. The existing guidelines recommended that patients who are intolerant to warfarin can be given direct oral anticoagulation (DOAC) to prevent DRT, followed by dual antiplatelet therapy for up to six months and then lifelong aspirin [11]. Previous clinical trials provided superior effect and safety of DOAC for post anticoagulation on patients developing LAAC operations, compared with antiplatelet treatment, with a lower DRT occurrence [12].

Recently, clinical trials prompted warning against advising anticoagulation with dabigatran in patients with mechanical heart valves mainly due to the enhancement of platelet aggregation [13]. Meanwhile, rivaroxaban, one selective Xa inhibitor, has been confirmed to decrease clot formation induced by thrombin. Furthermore, rivaroxaban remained favorable for patients with vascular thrombosis in the COMPASS trial [14]. Currently, some cases and retrospective trials reported the closure device-related thrombosis formation during anticoagulation with dabigatran in patients undergoing percutaneous LAAC [15]. The explanation for the failure of dabigatran to prevent DRT still remained unclear. Biomarkers such as thrombin-antithrombin complex (TAT), P-selectin, von Willebrand disease (vWF) and CD40L could reflect anticoagulation effect [16]. Therefore, the objective of this study was to evaluate platelet reactivity of different antithrombotic regimens under the condition of occluder implantation.

\section{Methods}

\section{Study design and population}

We conducted a single and prospective cohort study to investigate the efficacy and safety assessments of different DOACs (dabigatran and rivaroxaban) among patients with NVAF and undergoing percutaneous LAAC operations in the department of cardiology, Zhongshan Hospital, Fudan University between January 2018 and December 2019. Medical Ethics Committee of Zhongshan Hospital approved 
this study and waived the requirement for informed consent. According to European Society of Cardiology (ESC) criteria, NVAF was diagnosed [17]. All patients accepted electrocardiogram (ECG), showing a typical pattern of AF: absolutely irregular RR intervals and no discernible and distinct $\mathrm{P}$ waves.

\section{Study design}

In our study, a total of 105 patients were presented with high risk for stroke, transient ischemic attack, and systemic embolism with $\mathrm{CHA}_{2} \mathrm{DS}_{2}$-VASc score $\geq 2$ and deemed to be poor candidates for long-term DOAC. Consecutive patients were enrolled to perform successful LAAC operations with occluders. The main exclusion criteria were as follows: 1) history of bleeding and hemorrhagic disease, 2) concomitant anti-platelet medication, 3) severe renal dysfunction, 4) severe hepatic insufficiency, and 5) discontinuation of a treatment with dabigatran or rivaroxaban. Based on drug administration at admission, patients were categorized into two groups, namely the dabigatran (110 mg b.i.d.) or rivaroxaban (15mg q.d.) group.

\section{Medication and LAAC procedure}

In the preparation of LAAC procedure, the typical practice was to perform the implantation with uninterrupted dabigatran or rivaroxaban until operation day after admission. Briefly, the closures were implanted under general anesthesia and fluoroscopic guidance via the femoral vein and transseptal access. Intraprocedural transesophageal echocardiographic (TEE) was applied to rule out LAA thrombosis and define the LAA dimensions for device sizing. After the procedure, the sheath removed and hemostasis achieved with manual pressure or 8-stitch. The operation was conducted in a routine manner and patients obtained successful device implantation. All patients were medicated with 3-month course of anticoagulation with DOAC to facilitate device endothelialization, and followed by dual antiplatelet therapy until six months and then lifelong aspirin after discharge. The anticoagulant treatment was decided by attending physicians.

\section{Platelet aggregation measurement}

We applied thromboelastogram (TEG) to evaluate platelet aggregation induced with thrombin receptor activating peptide (TRAP, 32 $\mu \mathrm{M}$ ) after administration with dabigatran or rivaroxaban for 3 months. The mechanical electrical transducer was applied to monitor the coagulation status of the whole blood and we recorded the changes of amplitude with a computer during the thrombosis process. The maximum amplitude (MA) was defined as the largest change of coagulation intensity amplitude value.

The tested MA was classified into the thrombin-induced MA ( $\left(\mathrm{MA}_{\text {thrombin }}\right)$, the TRAP-induced MA (MA and the fibrin-induced $M A\left(M_{\text {Fibrin }}\right)$ according to three different activators added to the blood sample. The TRAP-induced platelet aggregation was calculated by the formula: TRAP induced platelet aggregation $(\%)=\left(\mathrm{MA}_{\text {thrombin }}-\mathrm{MA} \mathrm{A}_{\mathrm{TRAP}}\right) /\left(\mathrm{MA}_{\text {thrombin }}-\mathrm{MA}_{\text {Fibrin }}\right)$.

\section{Laboratory parameters}


Fasting blood samples $(2 \mathrm{ml})$ were collected to measure plasma coagulation markers mediate platelet activation including TAT, P-selectin, vWF and CD40L by the method of enzyme-linked immunosorbent assay (ELISA) kit recommended by the manufacturer on the same day of LAAC and at 3 months after operation procedure. The detection ranges were $2-100 \mathrm{ng} / \mathrm{mL}, 10-1000 \mathrm{ng} / \mathrm{L}, 20-500 \mathrm{U} / \mathrm{L}$ and $30-2400$ $\mathrm{ng} / \mathrm{L}$, respectively.

\section{Device related thrombosis (DRT)}

Similar to other implanted device into human body, thin layer of fibrin might form on the device membrane due to exposition to blood circulation. DRT was defined as a well-circumscribed echo-reflective mass on the left atrial side of the device defect and the thrombosis size was assessed by TEE. Outpatient follow-up visits were scheduled at each month after their discharge. During the follow-ups, repeated TEEs were carried out to evaluate thrombosis formation on occluders, left atrium/thrombus ratio, and the thrombus dissolution ability. As for the formation of DRT appearance, anticoagulation strategy switched from dabigatran or rivaroxaban to warfarin with the target INR of 2.0-3.0, and another TEE was scheduled to define thrombosis dissolution.

\section{Data collection and Follow-ups}

Detailed information about each subject such as history of smoking or alcohol consumption, comorbidity disease, levels of hemoglobin ( $\mathrm{Hb}$ ) and hematocrit (Hct), platelet (PLT) count, alanine aminotransferase (ALT), estimated glomerular filtration rate (eGFR), and cardiac biomarkers as well as concomitant drugs in use, were collected through electronic medical records on admission.

\section{Statistical analysis}

The descriptive statistics of continuous variables were expressed as means \pm standard deviations (SD), and those of discrete variables were expressed as counts or percentages. One-way independent Student's $\mathrm{t}$-tests was adopted to compare the differences of the continuous variables between the two groups of patients and chi-squared tests were performed to compare the distribution of categorical variables. The comparison of platelet aggregation was analyzed through Student t-test. For analyzing dynamic changes on platelet activation between dabigatran and rivaroxaban, we incorporated paired data for analyses for intraindividual intake of DOAC anticoagulation. We compared the plasma platelet activation expressions between DRT and non-DRT patients. We analyzed clinical risk associations of DRT occurrence by using multiple statistical models. Variables including $\mathrm{CHA}_{2} \mathrm{DS}_{2}-\mathrm{VAS}_{\mathrm{C}}$ score potential risk factors, age, LAA size, plasma platelet activation, TRAP induced platelet aggregation and anticoagulation treatment factors were analyzed. Odds ratios (ORs) with two-sided 95\% confidence intervals (Cls) were calculated for the risk factors of composite endpoint. Results are presented as ORs along with $95 \% \mathrm{Cl}$. Statistical analysis was conducted with SPSS (IBM SPSS Statistics 22.0) and Prism 5 (GrandPad Software). The P value of 0.05 was considered to be the threshold for statistical significance.

\section{Results}




\section{Patients' characteristics}

During the study inclusion period, a total of 105 consecutive patients with atrial fibrillation underwent percutaneous LAAC successfully and completed a 3-month follow-up with NOAC. Among the enrolled patients, about 33 received dabigatran (31.4\%) and 72 for rivaroxaban (68.6\%). Among the enrolled patients, 6 patients developed DRT with the TEE examine ( 3 for dabigatran and 3 for rivaroxaban) and switched to achieve the stabilization phase of warfarin anticoagulation (INR 2-3) until thrombosis resolution. The study design and progression of anticoagulation strategy were summarized in Fig. 1 .

Table 1 summarized the basic demographic and clinical characteristics of the patients. The two groups were well-matched with respect to age, gender and comorbidity including diabetes mellitus (DM), hypertension, stroke, and coronary artery disease $(P>0.05)$. There was no significant difference in the echocardiography parameters and closure size between two groups $(p>0.05)$.

The ratio with high thromboembolic risk according to $\mathrm{CHA}_{2} \mathrm{DS}_{2}$-VASc score of $>4$ was $55.6 \%$ for rivaroxaban and $70.8 \%$ for dabigatran, respectively. The majority high bleeding risk with a HAS-BLED score of $>3$ was $93.8 \%$ and $100 \%$ of cases for rivaroxaban and dabigatran anticoagulation, respectively. 
Table 1

Baseline characteristics of the study population

\begin{tabular}{|c|c|c|c|}
\hline Baseline Characteristics & $\begin{array}{l}\text { Rivaroxaban } \\
(n=72)\end{array}$ & $\begin{array}{l}\text { Dabigatran } \\
(n=33)\end{array}$ & $P$ value \\
\hline Age, years; mean (SD) & $69.04 \pm 8.96$ & $66.17 \pm 12.35$ & 0.218 \\
\hline Gender, male; n (\%) & $46.9 \%$ & $58.3 \%$ & 0.326 \\
\hline Smoking, n (\%) & $11.1 \%$ & $8.3 \%$ & 0.696 \\
\hline Alcohol, n (\%) & $4.9 \%$ & $4.2 \%$ & 0.876 \\
\hline \multicolumn{4}{|l|}{ Complication } \\
\hline Hypertension, n (\%) & $61.7 \%$ & $50.0 \%$ & 0.305 \\
\hline Hyperlipid, n (\%) & $7.4 \%$ & $4.2 \%$ & 0.576 \\
\hline Diabetes, n (\%) & $21.0 \%$ & $12.5 \%$ & 0.352 \\
\hline Stroke, n (\%) & $28.4 \%$ & $25.0 \%$ & 0.744 \\
\hline \multicolumn{4}{|l|}{ Imaging } \\
\hline LA, mm; mean (SD) & $49.04 \pm 7.612$ & $46.29 \pm 6.083$ & 0.109 \\
\hline LVDd, mm; mean (SD) & $47.78 \pm 5.812$ & $45.54 \pm 5.291$ & 0.094 \\
\hline LVDs, mm; mean (SD) & $31.02 \pm 5.126$ & $29.13 \pm 3.687$ & 0.094 \\
\hline LVEF, \%; mean (SD) & $63.48 \pm 6.762$ & $65.08 \pm 4.662$ & 0.281 \\
\hline LAA, mm; mean (SD) & $25.31 \pm 3.611$ & $24.63 \pm 3.132$ & 0.404 \\
\hline Closure size, mm; mean (SD) & $28.98 \pm 3.420$ & $28.13 \pm 3.301$ & 0.284 \\
\hline \multicolumn{4}{|l|}{ Laboratory tests } \\
\hline eGFR, $\mathrm{mL} /\left(\min \cdot 1.73 \mathrm{~m}^{2}\right)$; mean (SD) & $75.25 \pm 14.71$ & $80.71 \pm 21.16$ & 0.154 \\
\hline Hb, g/L; mean (SD) & $133.43 \pm 15.57$ & $130.50 \pm 19.30$ & 0.446 \\
\hline Hct, \%; mean (SD) & $39.79 \pm 4.15$ & $39.18 \pm 5.26$ & 0.559 \\
\hline $\mathrm{PLT}, 100 * 10^{9} / \mathrm{L} ;$ mean (SD) & $185.51 \pm 57.40$ & $205.96 \pm 53.31$ & 0.122 \\
\hline ALT, U/L; mean (SD) & $23.33 \pm 19.72$ & $24.04 \pm 14.16$ & 0.869 \\
\hline
\end{tabular}

The data are shown as mean (SD) or \%. SD, standard deviation; LA, left atrial; LVDd, left ventricular end diastolic dimension; LVDs, left ventricular end systolic dimension; LVEF, left ventricular ejection fraction; LAA, left atrial appendage; eGFR, estimated glomerular filtration rate; $\mathrm{Hb}$, hemoglobin; $\mathrm{Hct}$, hematocrit; PLT, platelet; ALT, alanine aminotransferase; AST, aspartate transaminase; APTT, activated partial thromboplastin time; $\mathrm{PT}$, prothrombin time; TT, Thrombin time; thrombosis and bleeding risk was represented with $\mathrm{CHA}_{2} \mathrm{DS}_{2}$-VASc and HAS-BLED score, respectively. 


\begin{tabular}{|c|c|c|c|}
\hline Baseline Characteristics & $\begin{array}{l}\text { Rivaroxaban } \\
(\mathrm{n}=72)\end{array}$ & $\begin{array}{l}\text { Dabigatran } \\
(n=33)\end{array}$ & $P$ value \\
\hline AST, U/L; mean (SD) & $24.16 \pm 13.63$ & $24.25 \pm 7.87$ & 0.976 \\
\hline APTT, s; mean (SD) & $29.17 \pm 5.14$ & $28.83 \pm 6.14$ & 0.783 \\
\hline PT, s; mean (SD) & $14.68 \pm 5.44$ & $13.48 \pm 4.24$ & 0.320 \\
\hline $\mathrm{CHA}_{2} \mathrm{DS}_{2}$-VASc; mean (SD) & $3.94 \pm 1.34$ & $4.33 \pm 1.47$ & 0.218 \\
\hline $\mathrm{CHA}_{2} \mathrm{DS}_{2}-\mathrm{VASc} \geq 2 ; \mathrm{n}(\%)$ & $100 \%$ & $100 \%$ & / \\
\hline $\mathrm{CHA}_{2} \mathrm{DS}_{2}-\mathrm{VASc} \geq 3 ; \mathrm{n}(\%)$ & $90.1 \%$ & $91.7 \%$ & 0.821 \\
\hline $\mathrm{CHA}_{2} \mathrm{DS}_{2}-\mathrm{VASc} \geq 4 ; \mathrm{n}(\%)$ & $55.6 \%$ & $70.8 \%$ & 0.181 \\
\hline HAS-BLED; mean (SD) & $3.69 \pm 0.89$ & $3.88 \pm 0.85$ & 0.372 \\
\hline HAS-BLED $\geq 3 ; n(\%)$ & $93.8 \%$ & $100 \%$ & 0.212 \\
\hline \multicolumn{4}{|c|}{$\begin{array}{l}\text { The data are shown as mean (SD) or \%. SD, standard deviation; } L A \text {, left atrial; } L V D d \text {, left ventricular } \\
\text { end diastolic dimension; LVDs, left ventricular end systolic dimension; LVEF, left ventricular ejection } \\
\text { fraction; } L A A \text {, left atrial appendage; eGFR, estimated glomerular filtration rate; Hb, hemoglobin; Hct, } \\
\text { hematocrit; PLT, platelet; ALT, alanine aminotransferase; AST, aspartate transaminase; APTT, activatec } \\
\text { partial thromboplastin time; PT, prothrombin time; TT, Thrombin time; thrombosis and bleeding risk } \\
\text { was represented with } \mathrm{CHA}_{2} \mathrm{DSS}_{2} \text {-VASc and HAS-BLED score, respectively. }\end{array}$} \\
\hline
\end{tabular}

\section{Comparison of TRAP induced platelet aggregation}

In our study, we calculated TRAP induced platelet aggregation independently of concomitant antiplatelet medication after 3 month anticoagulation. As shown in Fig. 2, the TRAP induced platelet aggregation was higher for patients medication with dabigatran $(62.9 \pm 6.3 \%)$ when compared to patients on rivaroxaban medication $(59.7 \pm 6.9 \%)$ during anticoagulation course $\left(P=0.028^{*}\right)$.

\section{Plasma platelet activation after DOAC intake}

We subsequently performed ELISA analysis to further investigate platelet activation on the duration of three months DOAC intake. As shown in Fig. 3, the plasma levels of TAT, P-selectin, vWF expression was significant higher after 3 months intake of dabigatran $(66.70 \pm 27.29 \mathrm{ng} / \mathrm{mL}$ vs. $53.17 \pm 13.37 \mathrm{ng} / \mathrm{mL}, P=$ $0.013 ; 42.54 \pm 14.37 \mathrm{ng} / \mathrm{L}$ vs. $28.14 \pm 11.04 \mathrm{ng} / \mathrm{L}, \mathrm{P}=0.001 ; 332.03 \pm 97.41 \mathrm{U} / \mathrm{L}$ vs. $268.21 \pm 55.17 \mathrm{U} / \mathrm{L}, \mathrm{P}$ $=0.020$, respectively) compared with plasma markers of platelet activation on the day of LAAC operation. Meanwhile, no significant difference was found in the changes of CD40L plasma levels on 3 months after operation procedure and the day of LAAC $(1826.90 \pm 88.11 \mathrm{ng} / \mathrm{L}$ vs. $1796.02 \pm 97.85 \mathrm{ng} / \mathrm{L}, \mathrm{P}=$ $0.183)$.

After receiving 3 months anticoagulation with rivaroxaban, the expressions of plasma platelet activation of TAT, P-selectin, VWF and CD40L showed no significant changes on 3 months after operation procedure 
and the day of LAAC $(52.83 \pm 13.83 \mathrm{ng} / \mathrm{mL}$ vs. $54.88 \pm 9.68 \mathrm{ng} / \mathrm{mL}, \mathrm{P}=0.305 ; 30.60 \pm 13.40 \mathrm{ng} / \mathrm{L}$ vs. $32.02 \pm 11.10 \mathrm{ng} / \mathrm{L}, \mathrm{P}=0.780 ; 279.06 \pm 65.40 \mathrm{U} / \mathrm{L}$ vs. $269.48 \pm 47.50 \mathrm{U} / \mathrm{L}, \mathrm{P}=0.317 ; 1754.37 \pm 83.76 \mathrm{ng} / \mathrm{L}$ vs. $1736.340 \pm 69.54 \mathrm{ng} / \mathrm{L}, \mathrm{P}=0.162$, respectively)

\section{DRT and platelet activation}

Clinical and TEE imaging follow-ups were available in all enrolled patients at 3 months. During the followup period, there were $3(4.2 \%)$ in rivaroxaban and $4(12.1 \%)$ in dabigatran group experiencing DRT events $(\mathrm{OR}=0.315,95 \% \mathrm{Cl}: 0.066-1.489, \mathrm{P}=0.129)$, respectively. In order to investigate if platelet aggregation contributed to DRT, the plasma platelet activation on the day of LAAC operation was compared between the DRT and non-DRT groups. We observed significant higher expressions of plasma platelet activation markers for DTR patients in terms of the P-selectin and VWF compared with non-DRT patients $(65.28 \pm$ $13.93 \mathrm{ng} / \mathrm{L}$ vs. $32.14 \pm 12.11 \mathrm{ng} / \mathrm{L}, \mathrm{P}=0.037 ; 501.92 \pm 106.48 \mathrm{U} / \mathrm{L}$ vs. $280.98 \pm 54.10 \mathrm{U} / \mathrm{L}, \mathrm{P}=0.045$; respectively), as shown in Fig. 4. There was no significant difference between the DRT and non-DRT patients with respect to the levels of platelet activation markers as TAT and CD 40L $(91.05 \pm 42.18 \mathrm{~g} / \mathrm{mL}$ vs. $49.76 \pm 16.07 \mathrm{~g} / \mathrm{mL}, \mathrm{P}=0.356$ and $1993.87 \pm 73.31 \mathrm{ng} / \mathrm{L}$ vs. $1761.70 \pm 70.43 \mathrm{ng} / \mathrm{L}, \mathrm{P}=0.058)$.

Multivariate logistic regression was performed to identify the independent associations of DRT occurrence with $\mathrm{CHA}_{2} \mathrm{DS}_{2}$-VASc score potential risk factors, age, LAA size, plasma platelet activation, TRAP induced platelet aggregation and anticoagulation treatment. By multivariate analysis, anticoagulation regimen $(P=0.022 ; O R=4.366,95 \% \mathrm{Cl}$ : $0.434-10.839)$ was an independent predictor for DRT in patients after LAAC operation, while non of the plasma platelet activation included was associated with DRT. (Table 2) 
Table 2

Multivariate logistic regression of the DRT occurrence with clinical risk factors

\begin{tabular}{|c|c|c|c|c|}
\hline Variables & SE & $P$ value & OR & $95 \% \mathrm{Cl}$ \\
\hline Age, y & 0.303 & 0.184 & 0.669 & $0.370-1.211$ \\
\hline Anticoagulation (Dabigatran, \%) & 3.152 & $0.022^{\star}$ & 4.366 & $0.434-10.839$ \\
\hline $\mathrm{CHA}_{2} \mathrm{DS}_{2}$-VASc score & 3.012 & 0.202 & 4.273 & $1.043-17.543$ \\
\hline $\mathrm{LAA}, \mathrm{mm}$ & 0.528 & 0.836 & 0.896 & $0.318-2.524$ \\
\hline TAT, $\mathrm{g} / \mathrm{mL}$ & 0.321 & 0.195 & 1.517 & $0.808-2.847$ \\
\hline P-selectin, ng/L & 0.806 & 0.173 & 1.125 & $0.950-1.132$ \\
\hline VWF, U/L & 0.155 & 0.138 & 1.259 & $0.929-1.706$ \\
\hline $\mathrm{CD} 40 \mathrm{~L}, \mathrm{ng} / \mathrm{L}$ & 0.011 & 0.612 & 0.995 & $0.947-1.016$ \\
\hline TRAP induced platelet aggregation & 0.947 & 0.149 & 0.255 & $0.040-1.631$ \\
\hline \multicolumn{5}{|c|}{$\begin{array}{l}\text { Values are expressed as number and \%. OR indicates odds rati; } 95 \% \mathrm{Cl} \text { indicated } 95 \% \text { confidence } \\
\text { interval. Multivariate logistic regression included TAT, P-selectin, vWF and CD } 40 \mathrm{~L} \text { as covariates along } \\
\text { with age, anticoagulation regimen, LAA size, TRAP induced platelet aggregation. } \mathrm{CHA}_{2} \mathrm{DS}_{2} \text {-VASc score } \\
\text { were also included as covariates. }\end{array}$} \\
\hline
\end{tabular}

\section{Discussion}

To the best of our knowledge, our study was first to investigate platelet reactivity of dabigatran and rivaroxaban for patients undergoing percutaneous LAAC operation. The results presented in this study indicated that dabigatran treatment could enhanced platelet aggregation and increase platelet reactivity compared with rivaroxaban. A direct association between anticoagulation strategy and DRT was found in our research and higher platelet activation markers were predominantly found in DRT patients during 3 months post anticoagulation. Thus, our data suggested that a strategy of uninterrupted rivaroxaban administration is being used routinely in patients during occluders implantation, as it had been shown to be superior in preventing peri-procedural DRT during the first three months after LAAC operation than dabigatran.

Many studies had provided potential clinical benefit of DOACs (mainly related with rivaroxaban) for post anticoagulation after LAAC operation $[18,19]$. But it is still uncertain on the optimal anticoagulation strategy due to sparse clinical trials conducted to compare direct clinical efficacy and safety between different DOACs for LAAC operation. As treatment with dabigatran was shown incomplete resolution of DRT in some cases, dabigatran treatment should be administrated cautiously after a newly closure implanted. Our results showed that patients with dabigatran had higher TRAP induced platelet aggregation compared with rivaroxaban anticoagulation $(62.9 \%$ vs. $59.7 \%, P=0.028)$. At present, there was few related literature on the mechanism of dabigatran induced thrombosis for LAAC operation. The 
probable explanation might be that medication with dabigatran could promote platelet aggregation through the enhancement of thrombin receptor density on thrombocytes, which contribute to formation of thrombosis [20]. The potential dabigatran enhanced platelet reactivity mainly mediated by activation of thrombin receptor peptides is the specificity of thrombin-induced platelet activation [21]. One previous study concluded that TRAP-induced platelet aggregation was enhanced in cardiovascular patients receiving dabigatran by the increased expression profile of thrombin receptors on the surface of platelets [22]. Meanwhile, rivaroxaban could contribute to attenuation for platelet activity and aggregation by inhibiting coagulation FXa which might increase platelet activity via Protease Activated Receptor-1 (PAR1) $[23,24]$.

The thromboembolism risk under direct thrombin inhibitors (Dabigatran) treatment has been widely discussed [25]. The elevated plasma TAT levels had been referred as an important coagulation parameter to detect a prothrombotic state [26]. We observed evaluated concentrations of TAT under medication with dabigatran, while no significant change was found for rivaroxaban. One previous study demonstrated that dabigatran might provoke inhibition of negative feed-back mechanism related to thrombin, thrombomodulin, and protein $\mathrm{C}$ formation, which leads to thrombin generation [27]. However, this thrombus formation makers rise did not lead to the incidence of DRT.

VWF has been involved in many pathological processes including coagulation and inflammation, which might facilitate the development of DRT [28]. In the present study, administration with dabigatran displayed an increasing expression of plasma vWF. The probable reason might be that dabigatran anticoagulation was associated with inflammation, endothelial dysfunction, and oxidative stress, increased expression of angiogenic and cell adhesion molecules [29].

The central molecular mechanism of platelet aggregation attributes to adhesion of activated platelets on leukocytes with interaction of platelet P-selectin and P-selectin glycoprotein ligand-1 on leukocytes [30]. Our results showed there was an increase in the expression of plasma P-selectin after long term dabigatran intake. According to previous experiment, P-selectin expression could facilitate the binding of platelet and leukocyte by the means of molecular cascades [31]. Meanwhile, this phenomenon was not found under rivaroxaban treatment. Furthermore, we noticed that occurrence of DRT was associated with higher expressions of P-selectin mainly due to enhancement of platelet reactivity. Another adhesive protein on platelet surface, named CD40L, also played an important role in the inaction of platelet and leukocytes [32]. No significant change was observed under either dabigatran and rivaroxaban anticoagulation.

Compared with dabigatran, the incident DRT was more uncommon at 90 days with rivaroxaban indicating that early rivaroxaban anticoagulation after implantation is largely protective. Meanwhile, the marked increase of DRT incidence at 3 months for post-implantation anticoagulation after LAAC operation with dabigatran suggested that dabigatran could enhance platelet reactivity in some LAAC operation patients. In our population, the follow-up TEE imaging displayed a higher ratio of DRT under anticoagulation with dabigatran, the adjusted post-anticoagulation therapy for LAAC was further needed. 


\section{Limitations}

We acknowledged many limitations in this study. First, the observational nature of the study limits our ability to draw an accurate conclusion. In the future, large prospective and randomized controlled trials are needed to evaluate clinical effect and adverse drug reaction of NOACs for LAAC operation patients. Second, the very low rate of DRT would render such a study impractical and a requisite large sample size needed to be collected in further study. Thirdly, we did not evaluate the clinical significance of devicerelated thrombosis in the occluder implantation population mainly as for the low event rate of DRT and thromboembolic events. Finally, we only collect the information on occurrence of DRT at the first followup TEE detect after implantation in the study. It is certainly true that DRT can occur early after device implantation, which might have an influence on the observation of DRT time.

\section{Conclusion}

DRT after LAAC has been acknowledged to have a strong correlation with the risks of postoperative stroke and systematic embolic events. Overall, our data provided an important addition to literature that has been largely limited to direct comparisons of efficacy and safety between DOACs for post anticoagulation of LAAC operations. Our findings may help guide decision-making in clinical settings. By avoiding peri-procedure DRT occurrence, it is possible that factor II inhibitors (dabigatran) usage might even be reduced, as they had been shown to increase expressions of platelet reactivity including TAT, Pselectin, and vWF. Also, we found that platelet activation was involved in many pathological processes including coagulation and inflammation and facilitate the development of DRT. Therefore, a strategy of uninterrupted factor Xa inhibitor administration could be used routinely in patients during occluders implantation, as they have been shown to be safe in preventing peri-procedural DRT. Of course, this remains to be proven in future clinical studies.

\section{Declarations}

\section{FUNDING}

This study was supported by the Project of Key Innovative Team of Shanghai Top-Level University Capacity Building in Clinical Pharmacy and Regulatory Science at Shanghai Medical School of Fudan University (NO. HJW-R-2019-66-19) and Shanghai "Rising Stars of Medical Talent" Youth Development Program - Youth Medical Talents - Clinical Pharmacist Program (SHWJRS(2019)_072)

\section{CONTRIBUTIONS}

(I) Conception and design: Q Lv and D Zhou; (II) Administrative support: J Ge, D Zhou; (III) Provision of study materials or patients: X Zhang, Q Jin; (IV) Collection and assembly of data: Y Li; (V) Data analysis and interpretation: X Li, Y Li; (VI) Manuscript writing: All authors; (VII) Final approval of manuscript: All authors 


\section{DATA AVAILABILITY}

The data used and/or analyzed in this study are available from the corresponding author on reasonable request.

\section{ETHICS STATEMENT}

This study was conducted in compliance with the Helsinki Declaration and Good Clinical Practice In review and was approved by the Ethics Committee of Zhongshan Hospital. A written informed consent was signed by all participants before the commencement of the clinical studies.

\section{References}

1. Iskandar S, Vacek J, Lavu M, Lakkireddy D (2016) Left Atrial Appendage Closure for Stroke Prevention: Devices, Techniques, and Efficacy. Cardiol Clin 34 (2): 329-351. https://doi.org/10.1016/j.ccl.2015.12.009

2. Reddy VY (2018) Left atrial appendage closure devices: A reasonable therapeutic alternative. Heart Rhythm 15 (2): 302-305. https://doi.org/10.1016/j.hrthm.2017.10.006

3. Reddy VY, Möbius-Winkler S, Miller MA, Neuzil P, Schuler G, Wiebe J, Sick P, Sievert H (2013) Left atrial appendage closure with the Watchman device in patients with a contraindication for oral anticoagulation: the ASAP study (ASA Plavix Feasibility Study With Watchman Left Atrial Appendage Closure Technology). J Am Coll Cardiol 61 (25): 2551-2556.

https://doi.org/10.1016/j.jacc.2013.03.035

4. Saw J, Nielsen-Kudsk JE, Bergmann M, Daniels MJ, Tzikas A, Reisman M, Rana BS (2019) Antithrombotic Therapy and Device-Related Thrombosis Following Endovascular Left Atrial Appendage Closure. JACC Cardiovasc Interv 12 (11): 1067-1076. https://doi.org/10.1016/j.jcin.2018.11.001

5. Boersma LV, Ince H, Kische S, Pokushalov E, Schmitz T, Schmidt B, Gori T, Meincke F, Protopopov AV, Betts T, Foley D, Sievert H, Mazzone P, De Potter T, Vireca E, Stein K, Bergmann MW (2017) Efficacy and safety of left atrial appendage closure with WATCHMAN in patients with or without contraindication to oral anticoagulation: 1-Year follow-up outcome data of the EWOLUTION trial. Heart Rhythm 14 (9): 1302-1308. https://doi.org/10.1016/j.hrthm.2017.05.038

6. Reddy VY, Doshi SK, Kar S, Gibson DN, Price MJ, Huber K, Horton RP, Buchbinder M, Neuzil P, Gordon NT, Holmes DR, Jr. (2017) 5-Year Outcomes After Left Atrial Appendage Closure: From the PREVAIL and PROTECT AF Trials. J Am Coll Cardiol 70 (24): 2964-2975. https://doi.org/10.1016/j.jacc.2017.10.021

7. Asmarats L, Cruz-González I, Nombela-Franco L, Arzamendi D, Peral V, Nietlispach F, Latib A, Maffeo D, González-Ferreiro R, Rodríguez-Gabella T, Agudelo V, Alamar M, Ghenzi RA, Mangieri A, Bernier M, Rodés-Cabau J (2019) Recurrence of Device-Related Thrombus After Percutaneous Left Atrial 
Appendage Closure. Circulation 140 (17): 1441-1443.

https://doi.org/10.1161/circulationaha.119.040860

8. Fauchier L, Cinaud A, Brigadeau F, Lepillier A, Pierre B, Abbey S, Fatemi M, Franceschi F, Guedeney P, Jacon P, Paziaud O, Venier S, Deharo JC, Gras D, Klug D, Mansourati J, Montalescot G, Piot O, Defaye P (2018) Device-Related Thrombosis After Percutaneous Left Atrial Appendage Occlusion for Atrial Fibrillation. J Am Coll Cardiol 71 (14): 1528-1536.

https://doi.org/10.1016/j.jacc.2018.01.076

9. Dukkipati SR, Kar S, Holmes DR, Doshi SK, Swarup V, Gibson DN, Maini B, Gordon NT, Main ML, Reddy VY (2018) Device-Related Thrombus After Left Atrial Appendage Closure: Incidence, Predictors, and Outcomes. Circulation 138 (9): 874-885.

https://doi.org/10.1161/circulationaha.118.035090

10. Gouin-Thibault I, Delavenne X, Blanchard A, Siguret V, Salem JE, Narjoz C, Gaussem P, Beaune P, Funck-Brentano C, Azizi M, Mismetti P, Loriot MA (2017) Interindividual variability in dabigatran and rivaroxaban exposure: contribution of $\mathrm{ABCB} 1$ genetic polymorphisms and interaction with clarithromycin. J Thromb Haemost 15 (2): 273-283. https://doi.org/10.1111/jth.13577

11. Glikson M, Wolff R, Hindricks G, Mandrola J, Camm AJ, Lip GYH, Fauchier L, Betts TR, Lewalter T, Saw J, Tzikas A, Sternik L, Nietlispach F, Berti S, Sievert H, Bertog S, Meier B (2020) EHRA/EAPCI expert consensus statement on catheter-based left atrial appendage occlusion - an update. Eurolntervention 15 (13): 1133-1180. https://doi.org/10.4244/eijy19m08_01

12. Bergmann MW, Betts TR, Sievert H, Schmidt B, Pokushalov E, Kische S, Schmitz T, Meincke F, Stein KM, Boersma LVA, Ince H (2017) Safety and efficacy of early anticoagulation drug regimens after WATCHMAN left atrial appendage closure: three-month data from the EWOLUTION prospective, multicentre, monitored international WATCHMAN LAA closure registry. Eurolntervention 13 (7): 877 884. https://doi.org/10.4244/eij-d-17-00042

13. Eikelboom JW, Connolly SJ, Brueckmann M, Granger CB, Kappetein AP, Mack MJ, Blatchford J, Devenny K, Friedman J, Guiver K, Harper R, Khder Y, Lobmeyer MT, Maas H, Voigt JU, Simoons ML, Van de Werf F (2013) Dabigatran versus warfarin in patients with mechanical heart valves. N Engl J Med 369 (13): 1206-1214. https://doi.org/10.1056/NEJMoa1300615

14. Sharma M, Hart RG, Connolly SJ, Bosch J, Shestakovska O, Ng KKH, Catanese L, Keltai K, Aboyans V, Alings M, Ha JW, Varigos J, Tonkin A, O'Donnell M, Bhatt DL, Fox K, Maggioni A, Berkowitz SD, Bruns NC, Yusuf S, Eikelboom JW (2019) Stroke Outcomes in the COMPASS Trial. Circulation 139 (9): 1134-1145. https://doi.org/10.1161/circulationaha.118.035864

15. Li X, Jin Q, Zhang X (2020) Closure Device-Related Thrombosis After Anticoagulation With Dabigatran in Patients Undergoing Percutaneous Left Atrial Appendage Closure: Case Reports and Literature Review. Front Pharmacol 11: 563920. https://doi.org/10.3389/fphar.2020.563920

16. Ceriello A, Novials A, Ortega E, Pujadas G, La Sala L, Testa R, Bonfigli AR, Genovese S (2014) Hyperglycemia following recovery from hypoglycemia worsens endothelial damage and thrombosis 
activation in type 1 diabetes and in healthy controls. Nutr Metab Cardiovasc Dis 24 (2): 116-123. https://doi.org/10.1016/j.numecd.2013.05.003

17. Kirchhof P, Benussi S, Kotecha D, Ahlsson A, Atar D, Casadei B, Castella M, Diener HC, Heidbuchel H, Hendriks J, Hindricks G, Manolis AS, Oldgren J, Popescu BA, Schotten U, Van Putte B, Vardas P (2016) 2016 ESC Guidelines for the management of atrial fibrillation developed in collaboration with EACTS. Eur Heart J 37 (38): 2893-2962. https://doi.org/10.1093/eurheartj/ehw210

18. Enomoto Y, Gadiyaram VK, Gianni C, Horton RP, Trivedi C, Mohanty S, Di Biase L, Al-Ahmad A, Burkhardt JD, Narula A, Janczyk G, Price MJ, Afzal MR, Atoui M, Earnest M, Swarup V, Doshi SK, van der Zee S, Fisher R, Lakkireddy DR, Gibson DN, Natale A, Reddy VY (2017) Use of non-warfarin oral anticoagulants instead of warfarin during left atrial appendage closure with the Watchman device. Heart Rhythm 14 (1): 19-24. https://doi.org/10.1016/j.hrthm.2016.10.020

19. Duthoit G, Silvain J, Marijon E, Ducrocq G, Lepillier A, Frere C, Dimby SF, Popovic B, Lellouche N, Martin-Toutain I, Spaulding C, Brochet E, Attias D, Mansourati J, Lorgis L, Klug D, Zannad N, HauguelMoreau M, Braik N, Deltour S, Ceccaldi A, Wang H, Hammoudi N, Brugier D, Vicaut E, Juliard JM, Montalescot G (2020) Reduced Rivaroxaban Dose Versus Dual Antiplatelet Therapy After Left Atrial Appendage Closure: ADRIFT a Randomized Pilot Study. Circ Cardiovasc Interv 13 (7): e008481. https://doi.org/10.1161/circinterventions. 119.008481

20. Achilles A, Mohring A, Dannenberg L, Grandoch M, Hohlfeld T, Fischer JW, Levkau B, Kelm M, Zeus T, Polzin A (2017) Dabigatran enhances platelet reactivity and platelet thrombin receptor expression in patients with atrial fibrillation. J Thromb Haemost 15 (3): 473-476.

https://doi.org/10.1111/jth.13595

21. Olivier CB, Weik P, Meyer M, Weber S, Anto-Michel N, Diehl P, Zhou Q, Geisen U, Bode C, Moser M (2016) TRAP-induced platelet aggregation is enhanced in cardiovascular patients receiving dabigatran. Thromb Res 138: 63-68. https://doi.org/10.1016/j.thromres.2015.10.038

22. Vinholt PJ, Nielsen C, Söderström AC, Brandes A, Nybo M (2017) Dabigatran reduces thrombininduced platelet aggregation and activation in a dose-dependent manner. J Thromb Thrombolysis 44 (2): 216-222. https://doi.org/10.1007/s11239-017-1512-2

23. Anand SS, Bosch J, Eikelboom JW, Connolly SJ, Diaz R, Widimsky P, Aboyans V, Alings M, Kakkar AK, Keltai K, Maggioni AP, Lewis BS, Störk S, Zhu J, Lopez-Jaramillo P, O'Donnell M, Commerford PJ, Vinereanu D, Pogosova N, Ryden L, Fox KAA, Bhatt DL, Misselwitz F, Varigos JD, Vanassche T, Avezum AA, Chen E, Branch K, Leong DP, Bangdiwala SI, Hart RG, Yusuf S (2018) Rivaroxaban with or without aspirin in patients with stable peripheral or carotid artery disease: an international, randomised, double-blind, placebo-controlled trial. Lancet 391 (10117): 219-229. https://doi.org/10.1016/s0140-6736(17)32409-1

24. Petzold T, Thienel M, Dannenberg L, Mourikis P, Helten C, Ayhan A, M'Pembele R, Achilles A, Trojovky K, Konsek D, Zhang Z, Regenauer R, Pircher J, Ehrlich A, Lüsebrink E, Nicolai L, Stocker TJ, Brandl R, Röschenthaler F, Strecker J, Saleh I, Spannagl M, Mayr CH, Schiller HB, Jung C, Gerdes N, Hoffmann T, Levkau B, Hohlfeld T, Zeus T, Schulz C, Kelm M, Polzin A (2020) Rivaroxaban Reduces Arterial 
Thrombosis by Inhibition of FXa-Driven Platelet Activation via Protease Activated Receptor-1. Circ Res 126 (4): 486-500. https://doi.org/10.1161/circresaha.119.315099

25. Chan N, Sobieraj-Teague M, Eikelboom JW (2020) Direct oral anticoagulants: evidence and unresolved issues. Lancet 396 (10264): 1767-1776. https://doi.org/10.1016/s0140-6736(20)32439-9

26. Castillo MM, Yang Q, Zhan M, Pan AY, Lawlor MW, Mast AE, Sood R (2019) Maintaining extraembryonic expression allows generation of mice with severe tissue factor pathway inhibitor deficiency. Blood Adv 3 (3): 489-498. https://doi.org/10.1182/bloodadvances.2018018853

27. Perzborn E, Heitmeier S, Buetehorn U, Laux V (2014) Direct thrombin inhibitors, but not the direct factor Xa inhibitor rivaroxaban, increase tissue factor-induced hypercoagulability in vitro and in vivo. J Thromb Haemost 12 (7): 1054-1065. https://doi.org/10.1111/jth.12591

28. Kawecki C, Lenting PJ, Denis CV (2017) von Willebrand factor and inflammation. J Thromb Haemost 15 (7): 1285-1294. https://doi.org/10.1111/jth.13696

29. Feinauer MJ, Schneider SW, Berghoff AS, Robador JR, Tehranian C, Karreman MA, Venkataramani V, Solecki G, Grosch JK, Gunkel K, Kovalchuk B, Mayer FT, Fischer M, Breckwoldt MO, Brune M, Schwab Y, Wick W, Bauer AT, Winkler F (2021) Local blood coagulation drives cancer cell arrest and brain metastasis in a mouse model. Blood 137 (9): 1219-1232.

https://doi.org/10.1182/blood.2020005710

30. Xia L, Sperandio M, Yago T, McDaniel JM, Cummings RD, Pearson-White S, Ley K, McEver RP (2002) P-selectin glycoprotein ligand-1-deficient mice have impaired leukocyte tethering to E-selectin under flow. J Clin Invest 109 (7): 939-950. https://doi.org/10.1172/jci14151

31. Chen QF, Li YZ, Wang XH, Su YR, Cui S, Miao MX, Jiang ZZ, Jiang ML, Jiang AD, Chen X, Xu YG, Gong GQ (2016) Evaluating antithrombotic activity of HY023016 on rat hypercoagulable model. Eur J Pharmacol 781: 190-197. https://doi.org/10.1016/j.ejphar.2016.04.023

32. Li G, Sanders JM, Bevard MH, Sun Z, Chumley JW, Galkina EV, Ley K, Sarembock IJ (2008) CD40 ligand promotes Mac-1 expression, leukocyte recruitment, and neointima formation after vascular injury. Am J Pathol 172 (4): 1141-1152. https://doi.org/10.2353/ajpath.2008.070633

\section{Figures}




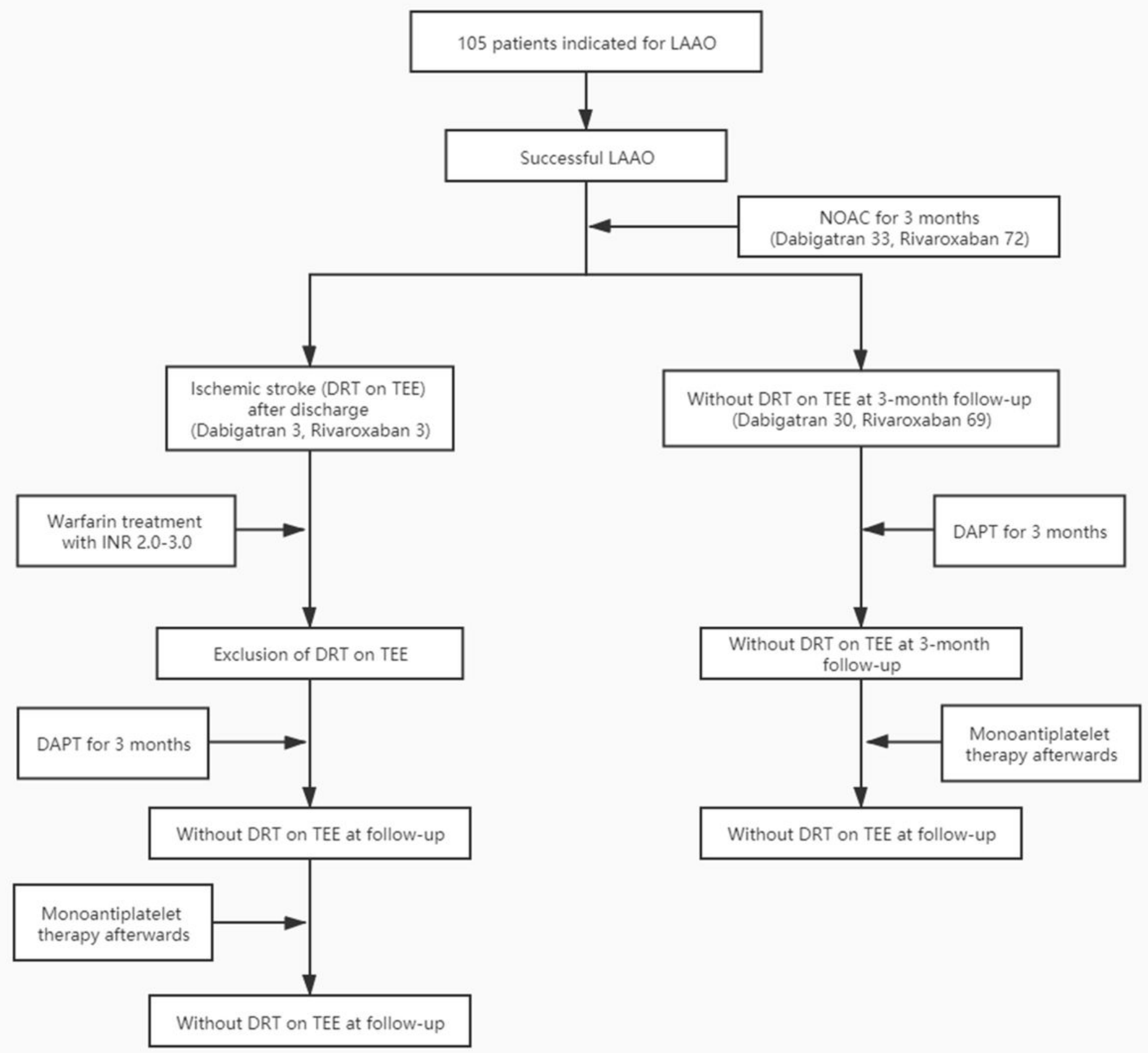

Figure 1

Diagrammatic presentation of our sample size and progression of anticoagulation strategy 


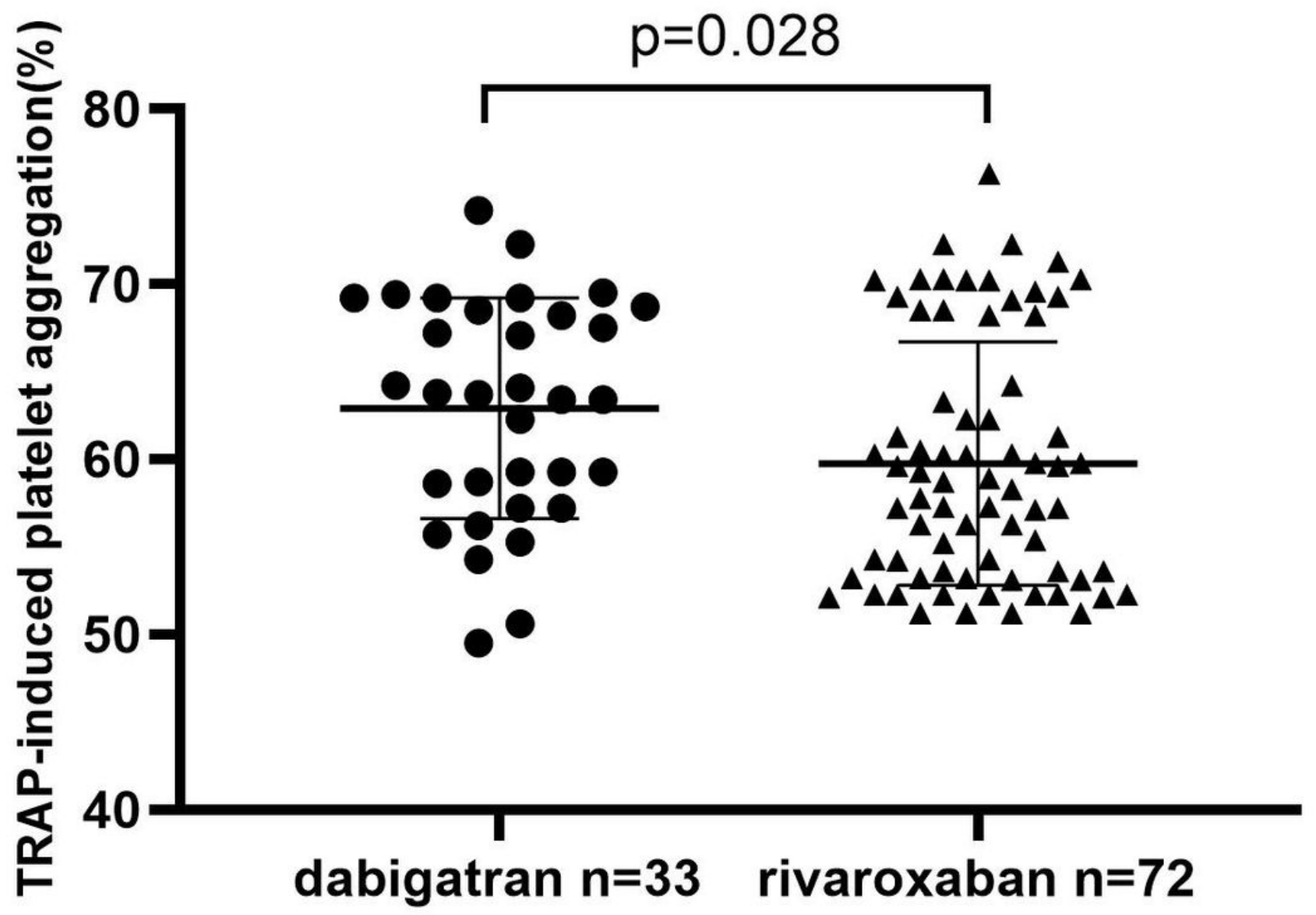

Figure 2

TRAP induced platelet aggregation comparison on dabigatran or rivaroxaban medication 

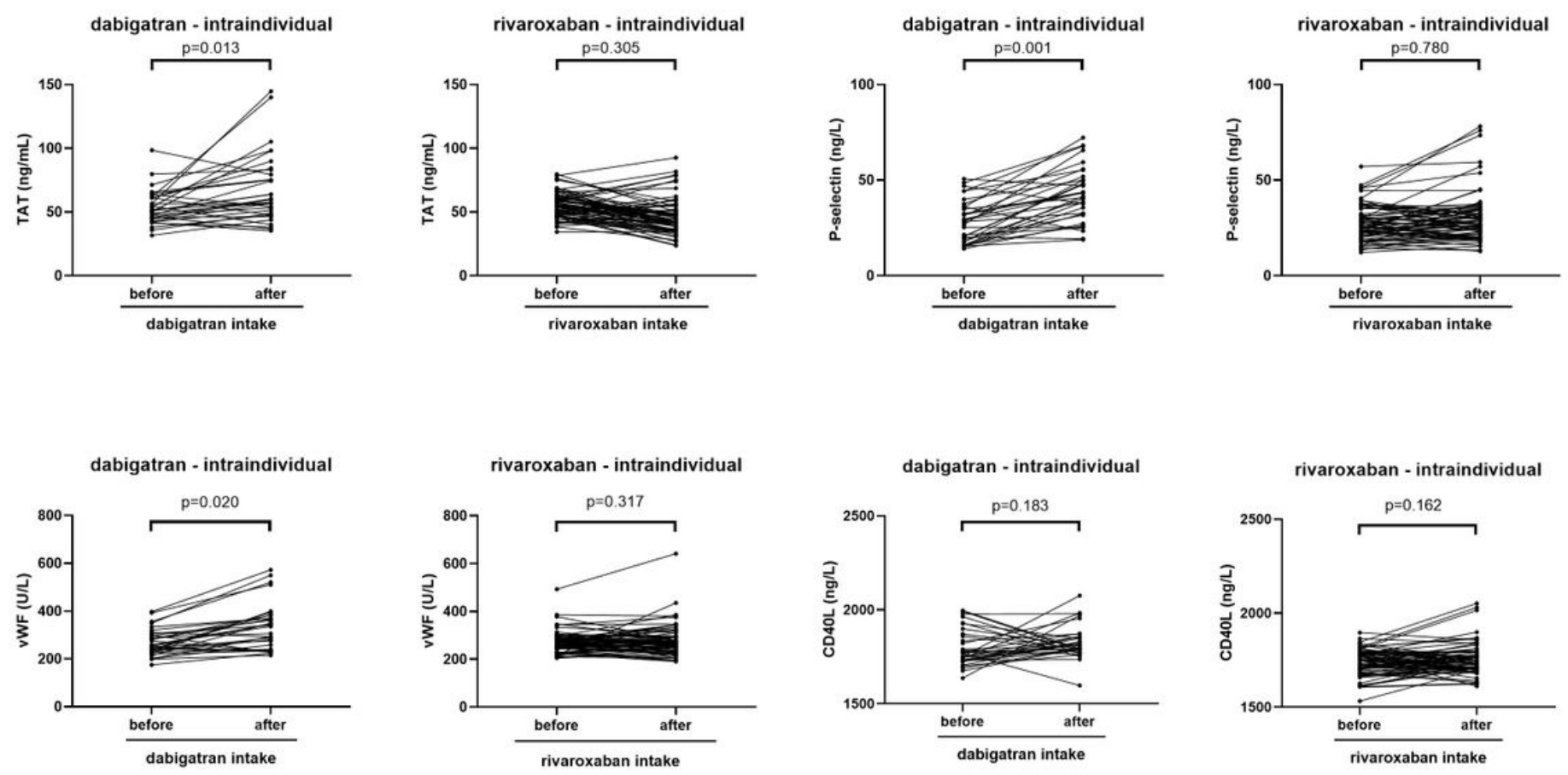

Figure 3

Intra-individual plasma platelet activation changes of patients before and after dabigatran or rivaroxaban medication. In an 3 months intraindividual follow-up, the platelet activation (TAT, P-selectin and vWF) increased significantly after the application of dabigatran compared with the measurement on the day of LAAC operation $(P<0.05)$. This was not seen in patients receiving rivaroxaban $(P>0.05)$. Meanwhile, CD40L showed no significant changes in either dabigatran or rivaroxaban group $(P>0.05)$. 

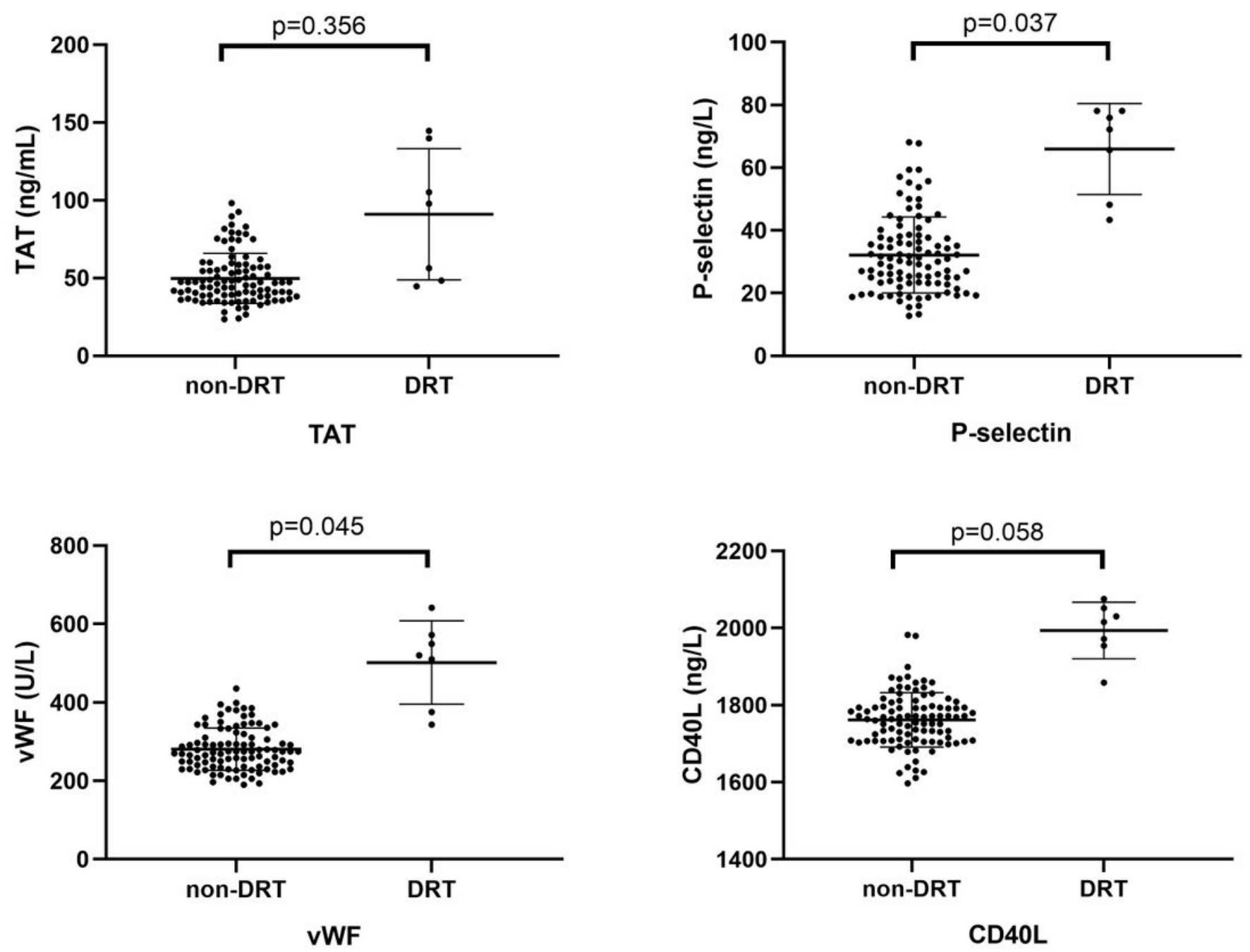

Figure 4

Comparison of platelet activation between the DRT and non-DRT groups. P-selectin and VWF plasma levels was significant higher in DRT compared with the measurement of non-DRT on the day of LAAC operation $(P<0.05)$. This was not seen in the TAT and CD40L $(P>0.05)$.

\section{Supplementary Files}

This is a list of supplementary files associated with this preprint. Click to download.

- Data.xlsx 